EESTI NSV TEADUSTE AKADEEMIA TOIMETISED. XIII KOIDE FUOSIKA-MATEMAATIKA- JA TEHNIKATEADUSTE SEERIA. 1964, NR. 1

ИЗВЕСТИЯ АҚАДЕМИИ НАУК ЭСТОНСКОЙ ССР. ТОМ ХІІ СЕРИЯ ФИЗИКО-МАТЕМАТИЧЕСКИХ И ТЕХНИЧЕСКИХ НАУК. 1964, № 1

\title{
ИССЛЕДОВАНИЕ ВЗАИМОДЕИСТВИЯ НЕКОТОРЫХ ФЕНОЛОВ С КЕТОНАМИ
}

\author{
A. AAPHA, \\ член-корреспондент Академии наук Эстонской ССР
}

Л. МЭЛДЕР,

кандидат технических наук

В наших предыдущих работах [1] исследовано взаимодействие фенола, $\alpha$-нафтола, $\beta$-нафтола и пирокатехина с простыми и сложными эфирами, аминами и спиртами. Было показано, что взаимодействие молекул фенольного характера с молекулами различных акцепторов протона приводит к образованию молекулярного комплекса при помощи водородной связи.

Молекулярные соединения фенолов с кетонами и хинонами известны уже давно $\left[{ }^{2-6}\right]$. Однако в более ранних работах ограничивались главным образом только физико-химическим анализом соответствующих систем с определением температуры плавления, вязкости и давления пара, не раскрывая истинной сущности явлений. Только Щмидлин -и Ланг [ $\left.{ }^{7}\right]$ в своей работе рассматривают процесс образования молекулярного соедннения как первую ступень реакции конденсации фенолов с кетонами.

Наконец, в течение последнего десятилетия появлялись многочисленные работы, посвященные теоретическому рассмотрению данного вопроса $\left[{ }^{8-13}\right]$.

Группа французских химиков исследовала изменения в инфракрасном спектре и спектре комбинационного рассеяния, обусловленные образованием молекулярного соединения [14-17]. При помощи измерения поглощения карбонильной группы им удалось доказать присутствие целогө ряда соединений типа фенол-кетон в растворе.

По теорин, предложенной Цубомура $\left[{ }^{18}\right]$, энергия молекулярного комплекса, обусловленного водородной связью, состоит из алгебраической суммы, слагаемыми которой являются: 1) электростатическая энергия, 2) дисперсионные силы, 3) силы отталкивания, 4) делокационная энергия, обусловленная переносом электрона от акцептора протона к донору протона.

Жербиер [13] утверждает, что для образования прочной водородной связи необходима близость колебательных уровней тех групп, которые находятся рядом с водородной связью. Например, частота колебания связи $\mathrm{C}=\mathrm{O}$ примерно дважды меньше частоты колебания связи О-H. Доказательством такого положения является открытие донорно-акцепторного взаимодействия между ацетоном и спиртами [23].

Уайдом, Филип и Хопс [19] предложили оригинальный метод для определения константы равновесия в растворе для систем фенол-кетон по инфракрасным спектрам. 
Мицушима и др. $\left[{ }^{20}\right]$ исследовали изменение ультрафиолетового спектра поглощения фенола, обусловленное образованием молекулярного комплекса, и определили константу равновесия и энергию связи соединения фенол-ацетон.

Изучение систем фенол-кетон представляет не только теоретический, но и практический ннтерес, так как во многих технических продуктах (например, в сланцевой смоле) фенолы и кетоны являются главными компонентами и знание их взаимодействия может быть основой усовершенствбвания технологических процессов. В литературе уже предложен ряд методов для обесфеноливания при помощи кетонов и «декетонизации» при помощи двухатомных фенолов [21, 22].

В настоящей работе исследовались константы равновесия и энергии связи некоторых систем фенол-кетон.

\section{Экспериментальная часть}

Методы очистки феновов и растворителей нами описаны ранеє [1].

Ацетон насыщали при $25^{\circ} \mathrm{C}$ сухим йодистым натрием, после чего жндкость сливали с осадка и охлаждали до - $15^{\circ}$; маточный раствор отделяли от кристаллов фильтрованием. Охлажденную соль переносили в колбу и нагревали до $35^{\circ}$. Жидкость помещали в перегонную колбу и перегоняли. Полученный продукт высушивался безводным поташом и дважды перегонялся в ректификационном аппарате.

Метилэтилкетон обрабатывали насыщенным раствором бисульфита натрия до полного выделения продукта присоединения, смесь охлаждали до $0^{\circ}$ и фильтровали, осадок дважды промывали эфиром и сушили. Из высушенного соединения кетон отгоняли с водяным паром. Кетон высаливали нз дистиллята поташом, обрабатывали едким калием и высушивали безводным поташом. Сухой продукт дважды перегоняли в ректификационном аппа́рате.

Циклогексанон очищали через бисульфитное соединение, которое разлагали карбонатом натрия, кетон перегоняли с водяным паром, высушивали безводным поташом и дважды перегоняли в ректификационном аппарате в вакууме.

Пинаколин сушили безводным поташом и дважды фракционировали.

Метилбутилкетон обрабатывали перманганатом калия и несколькө раз насыщенным раствором поташа (с целью удаления кислых примесей). После высушивания над безводным поташом продукт дистиллировали.

о-Метилцнклогексанон обрабатывали насыщенным раствором погаша, высушивали безводным поташом и фракционировали в вакууме.

Чнстота препаратов проверялась по перманганатной пробе (чувствительность $0,003 \%$ ), кислотности (чувствительность $0,001 \%$ ); температуре кипения, плотности и показателю преломления.

Определение содержания воды в кетоне по инфракрасному спектру затруднено, так как первый обертон валентного колебания карбонильной группы почти совпадает с полосом поглощения гидроксильной группы в воде. Возможна лишь проверка постоянства коэффициента поглощения кетонов в интервале $2,73-3,10 \mu$ в зависимости от метода очистки.

Методика определения констант равновесия, изменения изобарного потенциала и энергии связи по ультрафнолетовым спектрам поглощения намн опнсана ранее [1]. Константы равновесия вычислены по величинам 
поглощения комплекса при $2800 \AA, 2840 \AA, 3230 \AA$ и $3320 \AA$ соответственно для фенола, пирокатехина, $\alpha$-нафтола и $\beta$-нафтола. Внолне возможно, но менее точно измерение при некоторых других длинах волн.

Таблица : тем

Влияние концентрации акцептора протона на константу равновесия

1. Фенол-метилбутилкетон в изооктане. Концентрация фенола $2,50 \cdot 10^{-4}$ моль/л

\begin{tabular}{|c|c|c|c|}
\hline \multirow{2}{*}{$\begin{array}{c}\text { Темпе- } \\
\text { ратура, } \\
{ }^{\circ} \mathrm{C}\end{array}$} & \multicolumn{2}{|c|}{$\begin{array}{c}\text { Концентрация кетона, } \\
\text { моль/л }\end{array}$} & \multirow{2}{*}{$\begin{array}{c}\text { Констан- } \\
\text { та равно- } \\
\text { весия } \\
K\end{array}$} \\
\hline & $\mathrm{C}_{\mathrm{A}}{ }^{*}$ & $\mathrm{C}_{\mathrm{A}}{ }^{*}$ & \\
\hline $\begin{array}{l}20 \\
20 \\
20\end{array}$ & $\begin{array}{l}0,020 \\
0,020 \\
0,060\end{array}$ & $\begin{array}{l}0,060 \\
0,120 \\
0,120\end{array}$ & $\begin{array}{l}34,0 \\
33,0 \\
31,7\end{array}$ \\
\hline $\begin{array}{l}30 \\
30 \\
30\end{array}$ & $\begin{array}{l}0,020 \\
0,020 \\
0,060\end{array}$ & $\begin{array}{l}0,060 \\
0,120 \\
0,120\end{array}$ & $\begin{array}{l}27,2 \\
27,1 \\
26,6\end{array}$ \\
\hline $\begin{array}{l}40 \\
40 \\
40\end{array}$ & $\begin{array}{l}0,020 \\
0,020 \\
0,060\end{array}$ & $\begin{array}{l}0,060 \\
0,120 \\
0,120\end{array}$ & $\begin{array}{l}20,9 \\
20,9 \\
21,4\end{array}$ \\
\hline
\end{tabular}

2. а-Нафтол-метилэтилкетон в изооктане. Концентрация $\alpha$-нафтола $1,50 \cdot 10^{-4}$ моль/л

$\begin{array}{llll}20 & 0,045 & 0,135 & 17,7 \\ 20 & 0,045 & 0,270 & 18,0 \\ 20 & 0,090 & 0,270 & 16,8 \\ 40 & 0,045 & 0,135 & 10,2 \\ 40 & 0,045 & 0,270 & 10,4 \\ 40 & 0,090 & 0,270 & 10,6\end{array}$

3. В-Нафтол-циклогексанон в изооктане. Комиентрация В-нафтола $1,69 \cdot 10^{-4}$ моль/л

\begin{tabular}{l|lll}
\hline 20 & 0,035 & 0,105 & 29,6 \\
20 & 0,035 & 0,210 & 30,0 \\
20 & 0,070 & 0,210 & 28,9 \\
40 & 0,035 & 0,105 & 20,9 \\
40 & 0,035 & 0,210 & 20,1 \\
40 & 0,070 & 0,210 & $19,0 \pm$ \\
\hline
\end{tabular}

$$
\text { * CM. [1]. }
$$

Данные в таб́л. 1 показывают, что константа равновесия не зависнт от концентрацин акцептора протона (в пределах $0,015 \quad 0,210$ жоль/л).

В таб́л. 2 приведены константы равновесня при разных температурах, соответствующие им изменения изобарного потенциала и энергии связи для комплексов фенол-кетон, $\alpha$-нафтол-кетон, $\beta$-нафтол-кетон и пирожатехнн-кетон.

Как видно нз табл. 2 , комплексы ацетона с одноатомнымн феноламк 
Қонстанты равновесия, изменения изобарного потенциала и энергии связи систем фенол-кетон

\begin{tabular}{|c|c|c|c|c|c|c|c|}
\hline \multirow[t]{2}{*}{$\frac{N i}{\pi / \pi}$} & \multirow[t]{2}{*}{ Фенол } & \multirow[t]{2}{*}{ Кетон } & \multicolumn{2}{|c|}{$\begin{array}{c}\text { Константа равно- } \\
\text { весия } K\end{array}$} & \multicolumn{2}{|c|}{$\begin{array}{c}\text { Изменение изобар - } \\
\text { ного потенциала } \\
\Delta Z^{\circ} \text {, ккал/лоль }\end{array}$} & \multirow{2}{*}{$\begin{array}{c}\text { Энергия } \\
\text { связи } \\
\kappa \kappa а л / \text { лоль } \\
\Delta H .\end{array}$} \\
\hline & & & $t=20,0^{\circ}$ & $t=40,0^{\circ}$ & $t=20,0^{\circ}$ & $t=40,0^{\circ}$ & \\
\hline $\begin{array}{l}1 \\
2 \\
3 \\
4 \\
5 \\
6\end{array}$ & $\begin{array}{l}5 \\
0 \\
\text { I. } \\
0 \\
0\end{array}$ & $\begin{array}{l}\text { Aџетон } \\
\text { Метилэтилкетон } \\
\text { Метилбутилкетон } \\
\text { Пннаколин } \\
\text { Цнклогексанон } \\
\text { о-Метилциклогексанон }\end{array}$ & $\begin{array}{l}32,2 \\
30,1 \\
32,9 \\
28,5 \\
30,5 \\
18,0\end{array}$ & $\begin{array}{l}16,9 \\
16,7 \\
21,1 \\
18,0 \\
18,0 \\
10,0\end{array}$ & $\begin{array}{l}-2,02 \\
-1,98 \\
-2,03 \\
-1,95 \\
-1,98 \\
-1,68\end{array}$ & $\begin{array}{l}-1,82 \\
-1,82 \\
-1,97 \\
-1,86 \\
-1,86 \\
-1,48\end{array}$ & $\begin{array}{l}-5,9 \\
-5,4 \\
-4,1 \\
-4,4 \\
-4,8 \\
-5,4\end{array}$ \\
\hline $\begin{array}{r}7 \\
8 \\
9 \\
10 \\
11 \\
12\end{array}$ & $\begin{array}{l}5 \\
5 \\
5 \\
0 \\
\frac{1}{1} \\
\vdots\end{array}$ & $\begin{array}{l}\text { Ацетон } \\
\text { Метилэтилкетон } \\
\text { Метилбутилкетон } \\
\text { Пинаколин } \\
\text { Циклогексанон } \\
\text { о-Метилциклогексанон }\end{array}$ & $\begin{array}{l}21,4 \\
17,5 \\
24,6 \\
20,1 \\
45,0 \\
33,2\end{array}$ & $\begin{array}{l}10,8 \\
10,4 \\
16,1 \\
10,8 \\
26,7 \\
24,4\end{array}$ & $\begin{array}{l}-1,78 \\
-1,66 \\
-1,86 \\
-1,75 \\
-2,22 \\
-2,04\end{array}$ & $\begin{array}{l}-1,53 \\
-1,51 \\
-1,79 \\
-1,53 \\
-2,12 \\
-2,06\end{array}$ & $\begin{array}{l}-6,3 \\
-4,7 \\
-3,9 \\
-5,7 \\
-4,8 \\
-2,8\end{array}$ \\
\hline $\begin{array}{l}13 \\
14 \\
15 \\
16 \\
17 \\
18\end{array}$ & 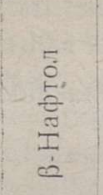 & $\begin{array}{l}\text { Ацетон } \\
\text { Метилэтилкетон } \\
\text { Метилбутилкетон } \\
\text { Пинаколин } \\
\text { Циклогексанон } \\
\text { о-Метилциклогексанон }\end{array}$ & $\begin{array}{l}26,4 \\
25,3 \\
25,2 \\
22,1 \\
29,5 \\
26,5\end{array}$ & $\begin{array}{l}11,9 \\
13,1 \\
16,5 \\
11,9 \\
20,0 \\
18,5\end{array}$ & $\begin{array}{l}-1,91 \\
-1,90 \\
-1,90 \\
-1,81 \\
-1,97 \\
-1,91\end{array}$ & $\begin{array}{l}-1,60 \\
-1,66 \\
-1,81 \\
-1,60 \\
-1,93 \\
-1,89\end{array}$ & $\begin{array}{l}-7,2 \\
-6,0 \\
-3,9 \\
-5,7 \\
-3,6 \\
-3,3\end{array}$ \\
\hline $\begin{array}{l}19 \\
20 \\
21 \\
22 \\
23 \\
24\end{array}$ & 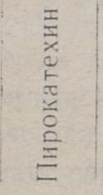 & $\begin{array}{l}\text { Ацетон } \\
\text { Метилэтилкетон } \\
\text { Метилбутилкетон } \\
\text { Пинаколин } \\
\text { Циклогексанон } \\
\text { о-Метилциклогексанон }\end{array}$ & $\begin{array}{l}111 \\
123 \\
140 \\
123 \\
236 \\
187\end{array}$ & $\begin{array}{c}57,4 \\
67,4 \\
72,2 \\
66,9 \\
120 \\
75,4\end{array}$ & $\begin{array}{r}-2,73 \\
-2,80 \\
-2,87 \\
-2,80 \\
-3,17 \\
-3,04\end{array}$ & $\begin{array}{r}2,62 \\
-2,71 \\
-2,76 \\
-2,71 \\
-3,08 \\
-2,76\end{array}$ & $\begin{array}{l}-6,0 \\
-5,5 \\
-6,1 \\
-5,5 \\
-6,2 \\
-8,3\end{array}$ \\
\hline
\end{tabular}

имеют нанбольшую энергию связи по сравнению с другими алифатическими кетонами.

У комплексов циклогексанона константа равновесия всегда больше, чем у метилциклогексанона. По всей вероятности при замещенных циклах пространственные факторы оказывают влияние. Из четырех фенолов наибольшей протонодонорной способностью обладает пирокатехин. Это полностью подтверждается большей склонностью двухатомных фе. нолов вступать в реакции конденсации с кетонами.

\section{Сводка}

1. Спектроскопическим методом определены для молекулярных комплексов фенол-кетон константы равновесия, изменения изобарного потенциала и энергии связи

2. Константы равновесия комплексов одноатомных фенолов с кетонами при $20^{\circ}$ находятся в пределах от 15 до 50 , двухатомных фенолов от 110 до 250.

3. Одноатомные фенолы обладают почти одинаковыми протонодонорными свойствами, но всегда меньшими, чем двухатомные фенолы

4. Энергия связи у всех систем в пределах от -3 до -8 ккал/моль.

\section{ЛИТЕ Р А Т У Р А}

1. А а рна А. Я., Мэлдер Л. И., Тр. Таллинск. политехн. ин-та, сер. А, 1960, № 185 , стр. 304: 1960, № 185, стр. 317; 1962, № 195, стр. 15: 1962, № 195, стр. 21

2. Meyer K. H., Ber, Bd. 42,1909 , S. $1149 ;$ Bd. 43,1910, S. 157. 
3. Krem a n n R., M a rkt 1 H., Monatshefte, Bd. 41, 1920, S. 43.

4. Kremann R., Sutter S., S itte F., Strzelba H., Dobotzky A., Monatshefte, Bd. 43,1922 , S. 270.

5. Weissenberger G., Herke R., Bregmann L., Monatshefte, Bd. 46, 1925, S. 471

6. Weissen berger G., Schus ter F., Monatshefte, Bd. 45,1925, S. 437.

7. S c h m id 1 in J., L a ng R., Ber., Bd. 43, 1910, S. 2806.

8. Sarna H. R., Treban-P. N., S ing h S., Res. Bull. Panjab. Univ., vol. 83, 1956, p. 4.

9. С а то И., Н агакура С., РЖХ, 10905, 1957.

10. Suzuki K., Seki S., Bull. Chem. Soc. Japan, vol. 26, 1953, p. 372.

11. W a 11 w ork S. C., H a rd in g T. T., Nature, vol. 171, No. 4340, 1953, p. 40.

12. Lee J. D., W a 11 w ork S. C., Acta Cryst., vol. 12, 1959, p. 210.

13. Ge r bier M.-M., G e r bier J., C. r. Acad. Sci., vol. 248, 1959, p. 669.

14. T a b our y F. J., Q u e uill e J., Bull. soc. chim. France, vol. 14, 1947, p. 772.

15. T a boury F. J., Lestra de M., Bull. soc. chim. France, vol. 14, 1947, p. 1026.

16. Lecomte J., Gra y E., T aboury F. J., Bull. soc. chim. France, vol. 14, 1947, p. 774 .

17. Gr a y E., Ann. chim., vol. 12, 1948, p. 355.

18. Isubomura H., Bull. Chem. Soc. par, vol, 27, 1954, p. 445.

19. Widom J. M., Phil ip pe R. J., Hob bs, M. E., J. Amer. Chem. Soc., vol. 79, 1957, p. 1383.

20. Mizushima S., Tsuboi M., Shimanouchi T., Tshuda Y., Spectrochim. acta, vol. 7,1955, p. 100.

21. Kow a lski J., S z c z urek B., Koks, smola, gas, vol. 3, 1958, p. 143.

22. K u b i čk a R., K v a p i 1 Z., Chem. Techn., Bd. 9, 1957, S. 661.

23. Pur a n i k P. G., Proc. Indian Acad. Sci., 1953, A 37, p. 499.

таллинский политехнический институт

Поступила в редакцию 29. V 1962

\title{
MÕNE FENOOLI JA KETOONIDE VAHELISEST TOIMEST
}

\section{A. Aarna,}

Eesti NSV Teaduste Akadeemia korrespondentliige

\author{
L. Mölder, \\ tehnikateaduste kandidaat
}

\section{Resümee}

Lähedases ultraviolettpiirkonnas tehtud spektroskoopiliste mõōmiste abil uuriti ternaarseid süsteeme, mis inertses lahustis (isoktaan) sisaldavad vähesel hulgal prootondoonorit ja prootonaktseptorit. Prootondoonoritena kasutati fenooli, $\alpha$-naftooli, $\beta$-naftooli jo pürokatehhiini, prootonaktseptoritena atsetooni, metüületüülketooni, metüülbutüülketooni, pinakoliini, tsükloheksanooni ja $o$-metüültsükloheksanooni. Vesiniksideme abil tekkinud kompleksidele määrati tasakaalukonstant $K$ temperatuuridel $20^{\circ} \mathrm{C}$ ja $40^{\circ} \mathrm{C}$. Tasakaalukonstandi temperatuursõltuvusest arvutati ühendi sideme energia $\Delta H$.

Tallinna Polütehniline Instituut

Saabus toimetusse

29. V 1962

\section{A STUDY OF THE INTERACTION OF SOME PHENOLS WITH SEVERAL KETONES}

\author{
A. Aarna, \\ Corresponding Member of the Academy of Sciences of the Estonian S.S.R. \\ L. Mölder
}

\section{Summary}

Measurements of near ultraviolet absorption were made with ternary systems containing small amounts of the proton donor and the acceptor in an inert solvent such as isooctane. Phenol, $\alpha$-naphthol, $\beta$-naphthol and catechol were used as the proton donor, and acetone, butanone-2, hexanone-2, pinacolin, cyclohexanone and $o$-methylcyclohexanone as the proton acceptor. The equilibrium constants $K$ of hydrogen-bonded complexes have been determined by means of measurements carried out at $20^{\circ} \mathrm{C}$ and $40^{\circ} \mathrm{C}$. The hydrogen bonding energy $\Delta H$ has been determined by measuring the temperature dependence of the equilibrium constant.

$$
\begin{gathered}
\text { Polytechnical Institute } \\
\text { of Tailinn }
\end{gathered}
$$

Received May 29th, 1962 